\title{
CATEGORIZATION AND ANALYSIS OF INDIGENOUS TRADITIONAL KNOWLEDGE PRACTICES (ITKS) ON RICE FARMING
}

\author{
V. MEENAKSHI ${ }^{1} \&$ J. VENKATA PIRABU ${ }^{2}$ \\ ${ }^{1}$ Research Scholar, Department of Agricultural Extension and Rural Sociology \\ Tamil Nadu Agricultural University, Coimbatore, Tamil Nadu, India \\ ${ }^{2}$ Professor and Head Training Division, Directorate of Extension Education \\ Tamil Nadu Agricultural University, Coimbatore, Tamil Nadu, India
}

ABSTRACT
Indigenous Technical Knowledge (ITK) is the actual knowledge of a given population that reflects the
experiences, based on tradition and includes more recent experiences with modern technologies (Haverkort, 1995). In
terms of Somasundaram (1995), indigenous knowledge is traditional knowledge that is based on accumulated experience, much
fitted to the local situation and social system. It is dynamic in nature.
KEYWORDS: Indigenous Technical Knowledge, Recent Experiences.\& Dynamic in Nature

Received: Sep 15, 2017; Accepted: Oct 05, 2017; Published: Oct 24, 2017; Paper Id.: IJESROCT201717

\section{INTRODUCTION}

Ganesamoorthi (2000) reported that the majority of the farmers were found to have a medium level of $59.38 \%$ perceived opinion, on post harvest technologies. Parvathi et.al. (2000) concluded in their study that, indigenous post harvest practices were perceived by the farm women, as economically feasible and user-friendly. The indigenous post harvest tools used by the women were made by local artisans, using low cost resources, which were locally available and they were easy to repair and to maintain and they did not require a higher degree of technical skill.

Eventually, this local knowledge in the course of time gets socially accepted and validated, which finally enters into the social life and subsequently become the Indigenous traditional knowledge (ITK) of the society, as a whole. Thus, socially validated indigenous knowledge which shares common values and gains popularity with a human element attached to it particularly the culture of the ethnic groups may be known by the name Indigenous traditional knowledge. However, now quiet recently it is known to people synonymously by various modern names such as indigenous technical knowledge, technical knowhow of indigenous people, people's knowledge etc. (Singh and Sureja, 2008).

\section{RESEARCH METHODOLOGY}

In this study, Indigenous Traditional Knowledge practices (ITKs) were identified in rice farming through informal interviews, with 120 aged and experienced farmers in 9 taluks of Thanjavur district of Tamil Nadu. Thanjavur district was purposively selected for the study, based on following reasons. 
- Thanjavur district is the one of indigenous traditional knowledge, practices intense district in rice farming.

- As research focuses on ITKs in rice farming, major consideration was given to this district, as it is the prime paddy belt.

Thanjavur district has nine taluks namely Budalur, Kumbakonam, Orathanadu, Papanasam, Pattukkottai, Peravurani, Thanjavur, Thiruvaiyaru and Thiruvidaimarudur, consisting of 837 revenue villages. Based on the discussion and interactions held with the Assistant Director of Agriculture, Agricultural Officers, Assistant Agricultural Officers and Subject Matter Specialists, it was found out that, the above selected villages had intense ITK practices under rice cultivation, as the valid evidence and testimonials for the selection was extracted for investigation.

\section{Selection of Respondents}

The respondents in the present study were rice farmers from the selected villages. A sample size of 240 was fixed for the study. For the selection of villages, an inventory of revenue villages in each of the taluk was prepared. The villages from each of the taluk were selected purposively, based on the intense ITK practices in rice cultivation. A total of 12 revenue villages were selected finally. A sample of 20 rice farmers was selected from each of the revenue villages from nine taluks, by adopting the simple random sampling method.

\section{Selection of Indigenous Traditional Knowledge Practices}

Indigenous traditional knowledge practices in rice farming system were selected for further study based on the following criteria.

- $\quad$ Area under cultivation of rice crop and its significance in the study area.

- Economic importance of the rice crop.

- The number and importance of indigenous traditional knowledge, practices available.

After deleting district specific indigenous traditional knowledge practices, 222 ITKs in rice were selected for further analysis in rice farming systems.

\section{RESULTS AND DISCUSSIONS}

\section{Spatial Distribution of Identified ITKs}

A look into the table provides us the details on totally identified ITKs, the number of blocks in which they are available and the actual number of ITKs identified. The total number of ITKs collected from all the 9 taluks was 222 of which 143 were actual ITKs available. The spatial distributions of collecting ITKs are enunciated in the following Table 1. 
Table 1: Spatial Distribution of Identified ITKs Over Different Taluks (n=120)

\begin{tabular}{|c|c|c|c|c|c|}
\hline \multirow{2}{*}{ S. No } & \multirow{2}{*}{ Spatial Distribution } & \multirow{2}{*}{$\begin{array}{c}\text { Number } \\
\text { of Identified } \\
\text { ITK Practices }\end{array}$} & \multirow{2}{*}{$\begin{array}{c}\text { Number of } \\
\text { Taluks in } \\
\text { which } \\
\text { Available }\end{array}$} & \multicolumn{2}{|c|}{$\begin{array}{c}\text { Actual ITK } \\
\text { Practices }\end{array}$} \\
\hline & & & & No. & $\%$ \\
\hline 1. & ITK practices found in any one taluk & 12 & 1 & 12 & 08.39 \\
\hline 2. & ITK practices found in any two taluks & 23 & 2 & 18 & 12.58 \\
\hline 3. & ITK practices found in any three taluks & 36 & 3 & 24 & 16.78 \\
\hline 4. & ITK practices found in more than three taluks & 68 & $4-9$ & 38 & 26.57 \\
\hline 5. & ITK practices found in all the nine taluks & 83 & 9 & 51 & 35.66 \\
\hline & Total & 222 & - & 143 & 100.00 \\
\hline
\end{tabular}

Of the 222 ITKs collected from all the taluks, some were available in any one of the taluk or any two or any three or more than three or in all the 9 taluks. Thus, the actual ITKs available from all the 9 taluks were 143, of which 12 ITKs $(8.39 \%)$ were found in any one of the nine taluks. There were 18 ITKs $(12.58 \%)$, which were available in any two of the taluks, 24 ITKs (16.78\%) in any three taluks, 38 ITKs (26.57\%) in more than three taluks and 51 ITKs (35.66\%), in all the nine taluks.

Those ITKs found in any one or two taluks alone were certainly taluk specific. For example, ITK Athur Kitchili Samba (yields $880 \mathrm{~kg}$ / hectare) rice variety present in Kumbakonam taluk alone. Likewise, the ITK practice, Applying aanai leaf (this gives thick green colour), as leaf manure in the nursery is present in Orathanadutaluk alone. The ITK practice, at flowering stage Egg solution (10 eggs of country breed hens were selected, crushed along with egg shells and soaked in cow urine and it is kept for 20 days) for a better seed set, which were available in any two of the taluks selected for the study. The ITK practice, Neem leaves Pungam leaves, Nochi, Erukku, Aadathoda leaves, Kolingi and thakkapoonduto control leaf sucking pests and shoots pests and is practiced in any of the three selected taluks. ITK practice Sheep Penning, is practiced in more than three taluks. ITK practice, Thanjavur rat trap is used for rat control and was found in all the nine taluks.

\section{Taluk Wise Categorization of ITKs}

Apart from the spatial distribution, all the collected ITKs were categorized taluk wise, so as to understand how many ITKs were found in each taluk and presented in Table 2. and figure. 1.

It was noted from the Table 2 that out of 222 ITKs collected, 53 ITKs $(23.87 \%)$ were found in Kumbakonam taluk, which had recorded the highest number of ITKs. Twenty five ITKs (11.26\%) were found in Papanasam taluk, 24 ITKs $(10.81 \%)$ in Thiruvaiyaru, 23ITKs $(10.36 \%)$ were found in Budalur taluk and Pattukkottai taluk, followed by 22 ITKs $(9.90 \%)$ were found in Orathanadu. Other taluks which has less than 20 ITKs include 19 ITKs (8.55\%) in Thiruvidaimarudur taluk, 18 ITKs (8.10\%) in Thanjavur taluk, 15 ITKs (6.75\%) in Peravurani taluk (Figure. 1.).

Table 2: Taluk Wise Categorization of Identified ITKs $(\mathbf{n}=120)$

\begin{tabular}{|c|l|c|}
\hline S. No & Name of the Taluk & ITK Practices (in Numbers) \\
\hline 1 & Budalur & 23 \\
\hline 2 & Kumbakonam & 53 \\
\hline 3 & Orathanadu & 22 \\
\hline 4 & Papanasam & 25 \\
\hline 5 & Pattukkottai & 23 \\
\hline 6 & Peravurani & 15 \\
\hline 7 & Thanjavur & 18 \\
\hline
\end{tabular}




\begin{tabular}{|c|l|c|}
\hline \multicolumn{3}{|c|}{ Table 2: Contd., } \\
\hline 8 & Thiruvaiyaru & 24 \\
\hline 9 & Thiruvidaimarudur & 19 \\
\hline \multicolumn{2}{|c|}{ Total } & $\mathbf{2 2 2}$ \\
\hline
\end{tabular}

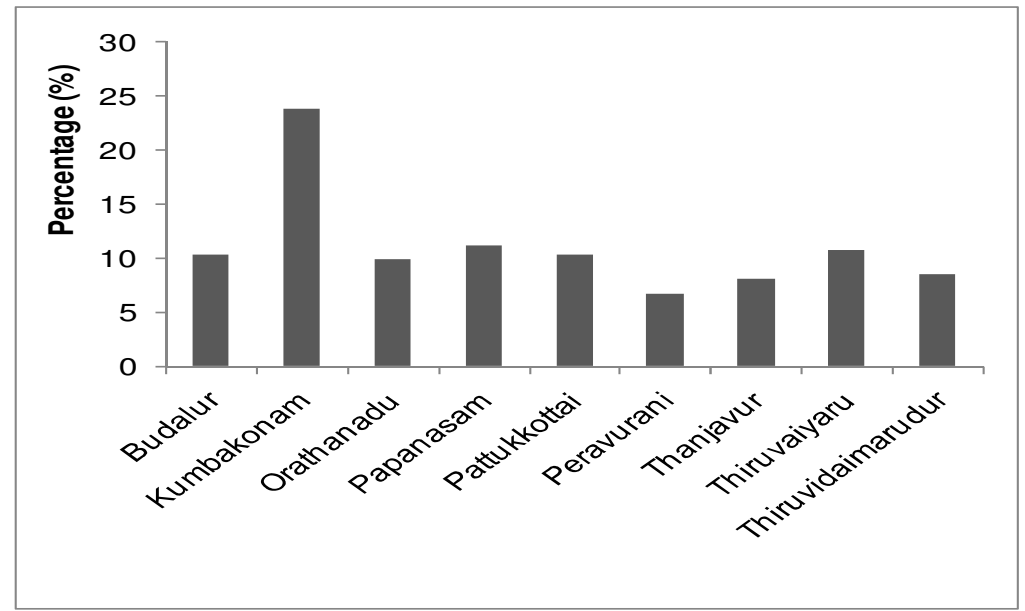

Figure 1: Taluk Wise Categorization of Identified ITKs in Percentage $(n=120)$

\section{Technology Wise Categorization of ITKs}

The collected available ITKs were classified according to the technological dimensions (Crop management, Crop improvement, Crop protection and Post harvest) to which they belong and the same has been given in the Table 3 and figure. 2 .

Table 3 indicates that 46.85 per cent of ITKs were related to crop management followed by 25.87 per cent of ITKs in post harvest technology, 22.37 percent in crop protection aspects and 4.89 percent in crop improvement aspects. Crop management aspect has acquired the higher number of ITKs. The important crop management practices in which ITKs have been established include seed treatment, nursery management, leaf manuring and the main field preparation.

Table 3: Technology Wise Categorization of Identified ITKs $(n=120)$

\begin{tabular}{|c|l|c|}
\hline S. No & \multicolumn{1}{|c|}{ Category } & ITK Practices (in Numbers) \\
\hline 1 & Crop management & 67 \\
\hline 2 & Crop improvement & 07 \\
\hline 3 & Crop protection & 37 \\
\hline 4 & Storage and post harvest & 32 \\
\hline & Total & $\mathbf{1 4 3}$ \\
\hline
\end{tabular}

In crop protection aspect, plant products and other natural substances had been used to control the pest and diseases and in post harvest aspect, storage and protection of seeds are done through plant products against storage pests. In these aspects, ITK practices were moderately utilized by farmers in all the taluks. Varietal (crop improvement) dimension had entered the least number of ITKs.

Until 1960's, the farmers had been cultivating very few crop varieties inherited from their ancestors. After the introduction of high yielding and high technology responsive varieties through government supported institutional research efforts, even those few indigenous varieties had started disappearing and losing their charm. This might be the reason for the existence of few indigenous varieties. 


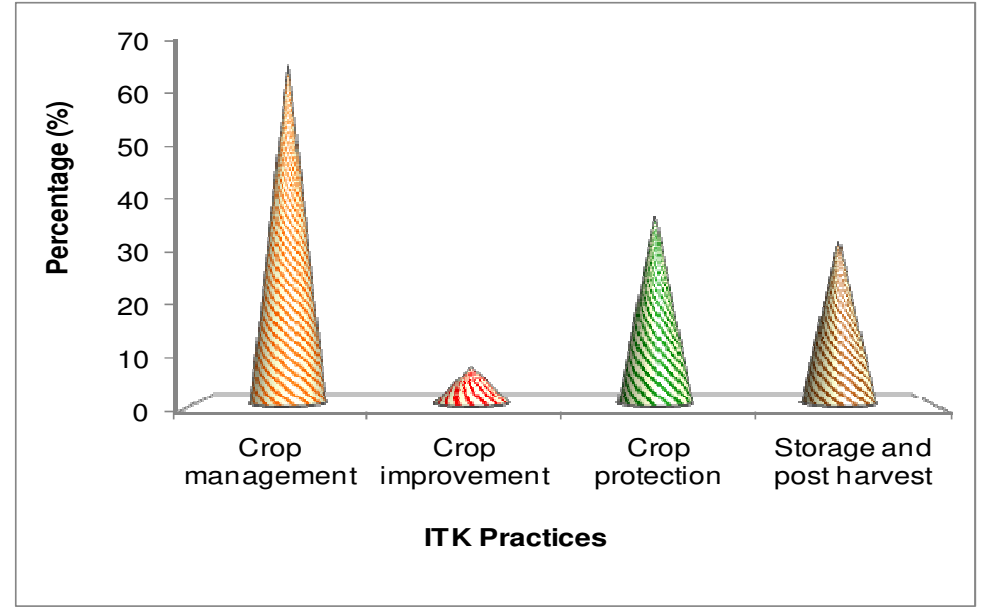

Figure 2: Technology Wise Categorization of Identified ITKs in Percentage (n=120)

\section{CONCLUSIONS}

The present study has brought out the existence of 143 ITKs on rice farming in the study area. These ITKs are very well categorized accordingly in spatial, taluk and technology wise to identify easily. The crop management aspect has acquired the higher number of ITKs. These ITKs may very well be documented, test verified, standardized, blended with modern technologies and recommended as alternatives.

\section{REFERENCES}

1. Ganesamoorthy, S. (2000). Indigenous knowledge on post harvest practices. Unpub. M. Sc. (Ag) Thesis, AC \& RI, TNAU, Coimbatore, Tamil Nadu.

2. Haverkort, Bertus. (1995). Agricultural Development with a Focus on Local Resources: ILEIA's view on Indigenous Knowledge. In: The Cultural Dimensions of Development: Indigenous knowledge systems (Eds.) D. M. Warren, L. J. Slikkerveer and D. Brokensha.1995: pp.454-457. Intermediate Technology Publications Ltd., London.

3. Parvathi. S, K. Chandrakandan and C. Karthikeyan, (2000). Women and dryland post - harvesting practices in Tamil Nadu, India. Indigenous knowledge \& Development Monitor, SCI: 13-16.

4. Singh, R. K and Sureja, A. K. (2008). Indigenous knowledge and sustainable agricultural resource management under rainfed agro- ecosystem. Indian journal of traditional knowledge, 7 (4): 642-654

5. Somasundaram, S. (1995). Indigenous Knowledge in Farming Systems. Un pub. Ph. D. (Ag.) Thesis, AC \& RI, TNAU, Coimbatore.

6. Sundaramari, M and T. T. Ranganathan. (2013). Indigenous Agricultural Practices for Suatainable Farming. Agrobios, Jodhpur.

\section{WEBSITES}

- $\quad$ www. thanjavur.tn. nic. in

- $\quad$ agcensus. nic. in

- http://agricoop.nic.in 
